OMAE2013-10778

\title{
C-HYP: A COMBINED WAVE AND WIND ENERGY PLATFORM WITH BALANCED CONTRIBUTIONS
}

\author{
Thomas Soulard \\ LUNAM Université \\ École Centrale de Nantes, CNRS \\ Nantes, FRANCE
}

\author{
Aurélien Babarit \\ LUNAM Université \\ École Centrale de Nantes, CNRS \\ Nantes, FRANCE
}

\author{
Bruno Borgarino \\ INNOSEA \\ Nantes, France
}

\author{
Mickael Wyns \\ TECHNIP \\ Paris la Défense, France
}

\author{
Migel Harismendy \\ TECHNIP \\ Paris la Défense, France
}

\begin{abstract}
This paper synthesizes the technical feasibility study carried out for a hybrid ocean energy converter, with balanced wind and wave contributions. The solution envisaged involves a $100 \mathrm{~m}$ diameter circular barge equipped with floating oscillating wave surge converters (OWSCs). This floating structure is mounted with a $5 \mathrm{MW}$ wind turbine. The present study covers power performance estimations, structural analysis and mooring design calculations. The first section describes the "Wave to Wire" model programmed in both frequency and time domain. The mathematical and hydrodynamic assumptions are highlighted together with the numerical model. The second part starts with the assessment of the performances of this device, carried out on in-house simulation codes. Based on combined wave and wind resources, the annual average absorbed power figures are compared with published results for existing ocean energy converters. The total rated power of the combined system reaches 10MW. Eventually, the last section approaches practical topics, directly related to the capital and operational costs inherent to an industrial development phase. The total steel mass is estimated first, from structural calculations carried out for a selection of 3D static loads cases. Then, a technical solution for the mooring system is presented together with the envisaged installation procedure.
\end{abstract}

Keywords - Wave energy converter, floating wind turbine, combined energy platform, structural analysis, moorings.

\section{INTRODUCTION}

The "MARINA Platform" project is a European initiative created to bring expertise from offshore wind industries together with ocean energy specialists, in order to reduce costs for deep water offshore platforms. Additional information is available on the project website [1]. The preliminary phases were focused on the benchmarking analysis of new and modified existing devices aiming at harnessing the different sources of ocean energies.

The present study lies within the second phase of the project, addressing the feasibility of a set of pre-selected concepts. It essentially focuses on one particular solution: the C-HyP. This Circular Hybrid Platform is a $100 \mathrm{~m}$ diameter floating platform, mounted with a 5MW wind turbine (WT) [7]. The wave facing semi-section of the barge is decomposed into twenty oscillating wave surge converters (OWSCs). Each independent absorber is linked to the platform through a Power take Off (PTO) system, transforming the mechanical power into an electrical output. A 3D picture of the system is shown in Figure 1, while the main dimensions are displayed in Table 1. Additional sketches from Figure 3 and Figure 4 provide details about the mass distribution and the OWSCs working range (highlighted in yellow below).

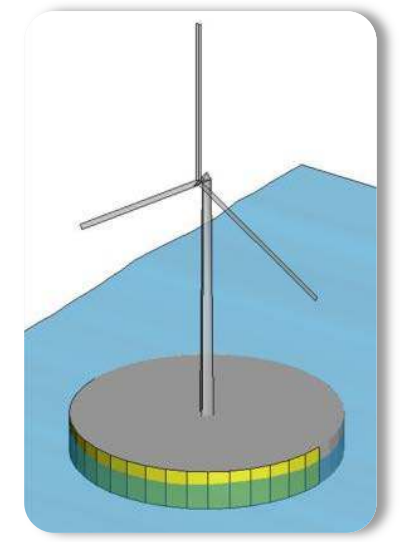

Figure 1: The C-HyP platform 


\begin{tabular}{lccl}
\hline Properties & Ref & Value & Units \\
Platform & & & \\
Radius & $\mathrm{R}$ & 50 & $\mathrm{~m}$ \\
$\begin{array}{l}\text { Draft } \\
\text { Displacement }\end{array}$ & $\mathrm{V}$ & 10 & $\mathrm{~m}$ \\
OWSCs & & & \\
WECs number & $\mathrm{N}$ & 20 & - \\
Width & $\mathrm{W}$ & 8 & $\mathrm{~m}$ \\
Wetted surface & $\mathrm{S}_{0}$ & 120 & $\mathrm{~m}^{2}$ \\
Mass & $\mathrm{m}_{\mathrm{i}}$ & 36 & $\mathrm{t}$ \\
Wind Turbine & & & \\
Rotor diam. & $\mathrm{d}_{\text {rotor }}$ & 126 & $\mathrm{~m}$ \\
Nacelle height & $\mathrm{z}_{\mathrm{N}}$ & 100 & $\mathrm{~m}$ \\
\hline
\end{tabular}

Table 1: Main dimensions of the platform C-HyP

The first section of this paper will focus on the non linearities implemented in the numerical "Wave to Wire" (W2W) model. The linear dynamic equations have been described in a previous publication [3], relying on proven modeling methods [2].

In a nutshell, the $\mathrm{W} 2 \mathrm{~W}$ code is based on linear potential theory for the fluid structure interactions. The hydrodynamic coefficients are calculated with the in-house BEM software Aquaplus [4]. In addition, three nonlinear phenomena are taken into account: the viscous forces, the aerodynamic loads and the end-stops limiting the excursion of the flaps. The main objective remains to determine the annual average power produced for a few selected geographical sites.

The initial results are promising and confirm the initial expectations for a balanced energy production. The different time domain simulations provided additional information related to the stability of the structure.

However, the large dimensions of the C-HyP platform can represent a drawback in terms of costs. A phase of structural analysis if therefore required at this early stage of development. Preliminary finite element calculations provided an estimate for the total steel mass of the C-HyP.

Eventually, the definition of the mooring system remains a major step in the feasibility study of such a floating platform. Different configurations have been tested in order to select the appropriate technical solution, from which a project cost can be estimated.

\section{1 - WAVE TO WIRE MODELLING}

\section{1 - Numerical approach}

The hypothesis and assumptions taken into account to create the numerical wave to wire model have been extensively detailed in [3]. The waves are supposed to be monodirectional propagating along the $\mathrm{x}$-axis, and the loads are linearized under the small amplitude approximation.

The motion of the barge is determined with three degrees of freedom (DOFs): $x_{0}$ in surge, $z_{0}$ in heave et $\theta_{0}$ in pitch. Each Wave Energy Converter (WEC) is represented as an additional
DOF $r_{i}$, defining the excursion from its equilibrium position. The different elements of the system are characterized by a mass and a center of mass : $\left(G_{0}, M_{p}\right)$ for the barge, $\left(G_{i}, m_{i}\right)$ for the WEC $i,\left(\mathrm{G}_{\mathrm{WT}}, \mathrm{M}_{\mathrm{WT}}\right)$ for the wind turbine. The angular location of the WEC is referred by the parameter $\alpha_{\mathrm{i}}$, taken between $\left[-\frac{\pi}{2} ; \frac{\pi}{2}\right]$.

Table 2 summarizes the different forces implemented in the W2W model and detailed in [3], insisting mostly on the physical aspects. The additional nonlinear loads implemented afterwards will be detailed in the section 1.2 to 1.4.

\begin{tabular}{|c|c|c|}
\hline Loads & Linear & Details \\
\hline Excitation & $\mathrm{x}$ & $\begin{array}{l}\text { Expressed at the gravity center of the } 21 \\
\text { bodies (considered independent). The loads } \\
\text { represent the interactions between the } 23 \\
\text { DoFs ( } 20 \text { excursions and surge/heave/pitch } \\
\text { of the platform). Loads calculated using the } \\
\text { in-house software Aquaplus. }\end{array}$ \\
\hline Hydrostatic & $\mathrm{x}$ & $\begin{array}{l}\text { Defined at the buoyancy center of each } \\
\text { bodies by integration of the pressure at the } \\
\text { equilibrium after a small perturbation. The } \\
\text { WECs' contribution is considered as an } \\
\text { external load for the system } \\
\text { \{Platform+WT+ballast\}. }\end{array}$ \\
\hline Gravity & $\mathrm{x}$ & $\begin{array}{l}\text { Vertical force in the global coordinate } \\
\text { system applied at the CoG of each body. }\end{array}$ \\
\hline Bearings & $\mathrm{x}$ & $\begin{array}{l}\text { A perfect reaction is applied to the flaps to } \\
\text { compensate for the static part of the } \\
\text { hydrostatic force. The reaction on the } \\
\text { platform is taken into account. }\end{array}$ \\
\hline PTO & $\mathrm{x}$ & $\begin{array}{l}\text { The hydraulic system is represented by } \\
\text { stiffness and damping coefficients. The force } \\
\text { is applied at the center of mass of the WECs } \\
\text { and directly proportional to the excursion } r \\
\text { and the speed } \dot{r}_{i} \text {. }\end{array}$ \\
\hline Moorings & $\mathrm{x}$ & $\begin{array}{l}\text { Initially represented as a horizontal spring } \\
\text { and a static contribution to compensate for } \\
\text { the horizontal static wind force. Additional } \\
\text { mooring simulations were performed by } \\
\text { TECHNIP. }\end{array}$ \\
\hline End stops & & $\begin{array}{l}\text { The maximum excursion is set to } 5 \mathrm{~m} \text { by } \\
\text { default. A large stiffness value is applied } \\
\text { through an Heaviside function. }\end{array}$ \\
\hline Ballast & $\mathrm{x}$ & $\begin{array}{l}\text { The ballast is considered as an additional } \\
\text { point mass body, in order to balance the } \\
\text { horizontal wind and gravity forces applied on } \\
\text { the WT. }\end{array}$ \\
\hline Wind & & $\begin{array}{l}\text { TDHMILL method applying lookup tables } \\
\text { for a given value of the relative wind speed } \\
\text { at the Nacelle } \mathrm{N} \text {. }\end{array}$ \\
\hline Viscous & & $\begin{array}{l}\text { Morison elements on the platform and on the } \\
\text { WECs. }\end{array}$ \\
\hline
\end{tabular}

Table 2: Summary of the loads implemented in the W2W model. 


\section{2 - Hydro-aero-dynamic coupling}

The method selected to simulate the aerodynamic loads has been inspired by the procedure presented in [5]. The resulting force is assumed to be horizontal and applied at the nacelle represented by the point $N\left(x_{N}, 0, z_{N}\right)$. The amplitude of the force depends on the relative wind speed $\operatorname{Vrel}_{x}(N, t)=V_{0}-V_{x}(N, t)$ and follows the trends published in [6]. Practically, the force $F$ wind $(t)$ is updated at each time step, with a value taken from a lookup table displayed in red on Figure 2. In the static case, $F$ wind $(t=0 s)=F$ wind $\left(V_{0}\right)$ only depends on the mean wind speed $V_{0}$.

Similarly, the electrical power output is directly extracted for the wind turbine power curve plotted black in Figure 2.

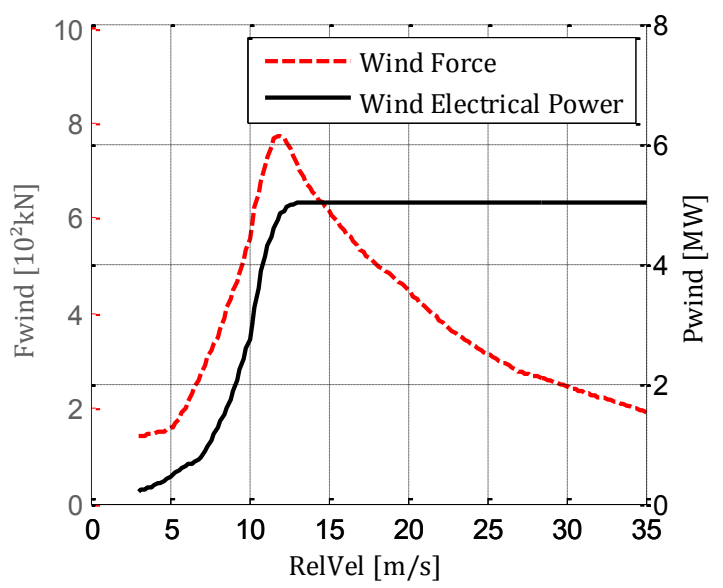

Figure 2: Force and power lookup tables, taken from [5].

Time domain simulation results validating the implementation of the method will be presented in section 2 .

\section{3 - Ballasting}

The static wind loads, mentioned in the previous section, applied at the nacelle create a static pitch momentum. In order to obtain a horizontal static equilibrium position a ballast was implemented in the model. Thus, a punctual mass $\left(\mathrm{G}_{1}, M_{\text {ballast }}\right)$ is placed at the distance $r_{1}=0.5\left(R-r_{0}\right)$ from the platform center of mass (see Figure 3).

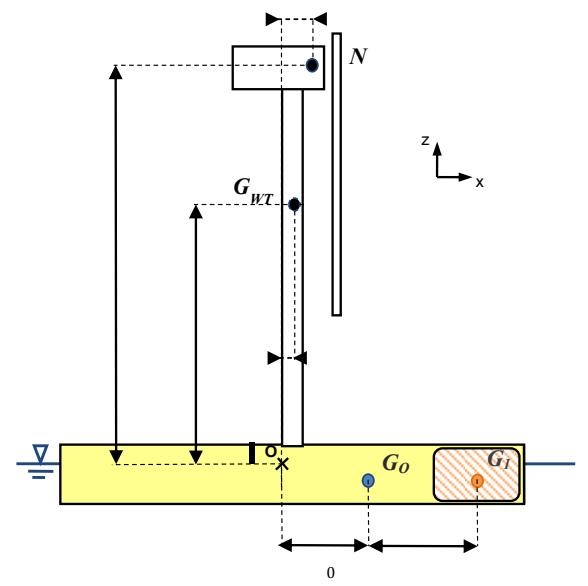

Figure 3: Sketch of the platform ballast.
The ballast mass required to cancel the static pitch momentum for the system $\{$ barge $+\mathrm{WT}+\mathrm{WECs}\}$ is given by:

$$
\begin{aligned}
& M \quad=-\frac{F \operatorname{wind}\left(V_{0}\right) z_{N}}{\left(x_{W T}-r_{0}\right) M} \\
& \sum \quad\left(r_{0}-o s \alpha_{i}\right)
\end{aligned}
$$

Following the nomenclature presented in [3], the ballast loads applied on the barge can be written as a gravity loads at $G_{0}$ :

$$
\left.\left(G_{0}\right)=\begin{array}{r}
0 \\
-M \\
M^{0} \\
0
\end{array}\right)
$$

The platform inertia matrix (mass and inertia) has to be modified to take into account the ballast:

$$
\begin{array}{lll}
M_{P}{ }^{\prime} & =M_{P}-M \\
I \quad=I \quad{ }^{2} M \\
I \quad=I \quad=I \quad-r_{1} M
\end{array}
$$

Practically, a seawater ballast system seems to be an appropriate technical solution.

\section{4 - Viscous forces}

A quadratic damping term was implemented in the model in order to represent viscous effects. As a first step, vertical and horizontal forces are applied at $P_{i}$ located on the deepest edge of the WEC $i$. Figure 4 suggests a representation of the viscous forces with a side view of the submerged section of the platform.

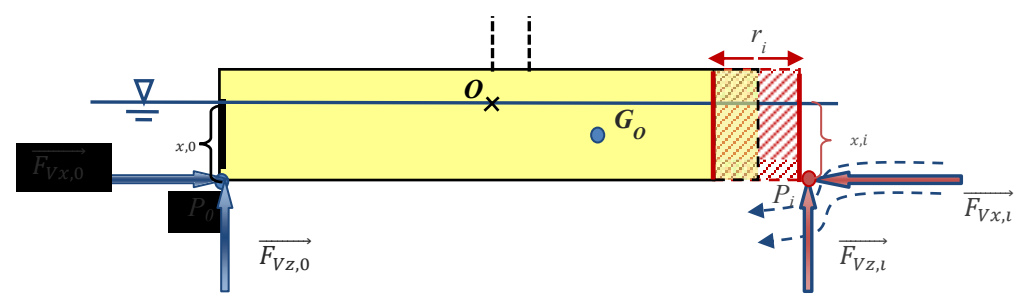

Figure 4: Sketch of wetted C-HyP surface with a representation of the viscous loads.

The viscous loads are proportional to the square of the relative fluid speed at $P_{i}$, and can by expressed by:

$\overrightarrow{F_{V, l}}=-F_{V x, i} \vec{n}-F_{V Z, i} \bar{m}$

knowing that $\vec{n}$ and $\vec{m}$ are the normal vectors at the surfaces surrounding the WEC after the excursion $r_{i}$. Furthermore:

$$
\begin{aligned}
& F_{V x, i}=\frac{1}{2} \rho C_{D x, i} A_{x, i}\left\|\vec{V}_{0}\left(P_{i}\right)-\vec{V}_{0, f l}\left(P_{i}\right)\right\|\left(\vec{V}_{i}\left(P_{i}\right)-\vec{V}_{i, f l}\left(P_{i}\right)\right) \cdot \vec{x} \\
& F_{V z, i}=-\frac{1}{2} \rho C_{D z, i} A_{z, i}\left\|\vec{V}_{0}\left(P_{i}\right)-\vec{V}_{0, f l}\left(P_{i}\right)\right\|\left(\vec{V}_{i}\left(P_{i}\right)-\vec{V}_{i, f l}\left(P_{i}\right)\right) \cdot \bar{z}
\end{aligned}
$$


The damping coefficients were chosen according to [8]: $\mathrm{C}_{\mathrm{Dx}, \mathrm{i}}=$ 3 (semi thin plate) and $C_{D z, i}=10$ (semi cylinder). The area $A_{x}$, is equal to the wetted surface of the WEC, and $A_{z, i}$ corresponds to the angular section of the horizontal surface, centered in $G_{0}$, which chord is equal to the flap. This force creates a momentum at the center of mass of the platform $\overrightarrow{\mathcal{M}_{\mathrm{V}, \mathrm{l}}}\left(\mathrm{G}_{0}\right)=$ $\overrightarrow{\mathrm{G}_{0} \mathrm{P}_{1}} \times \overrightarrow{\mathrm{F}_{\mathrm{V}, 1}}$.

Then, as a second step, the effect of the viscosity on the platform itself is estimated with a similar method. Indeed, the barge can be discretized into 20 angular sections. The integration of each component provides the resulting force applying at $P_{0}$ and the induced momentum at $G_{0}$.

\section{2 - SIMULATION RESULTS AND PERFORMANCES}

\section{1 - Wind and wave power coupling}

Based on the W2W model described earlier, the power outputs of the C-HyP concept could be calculated for different wind and wave conditions. Preliminary time domain simulations showed that the modularity inherent to a system with 20 different WECs comes with additional benefits. Indeed, knowing that each flap will absorb power with a different phase, the total electrical power output is likely to be smoother [3]. The normalized standard deviation of the total power is decreased by a factor two compared to one single WEC. Such a characteristic can significantly reduce the installation cost with a lower power cable rating or the need for onboard energy storage systems.

Nevertheless, the MARINA project mainly focuses on the feasibility of combined wind and wave concepts, knowing that the maturity of the wind technology is higher. Therefore, it is essential to verify that the implementation of the WECs will not disturb the wind power absorption.

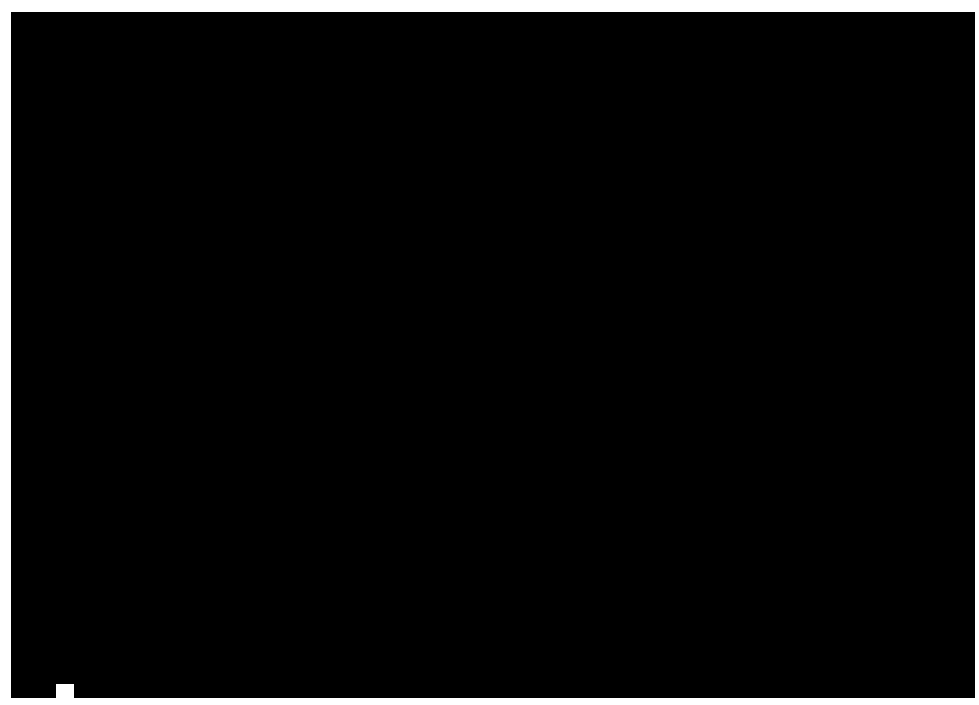

Figure 5: Wind and wave power curves for the wind driven approach.
Figure 5 shows the power outcomes of the "wind driven" approach. In other words, for a given geographical site, one can obtain the mean wind speed distribution (red area on the graphic). A time domain run is then carried out for the most propable sea state for the selected wind speed. Hence, the results of each run can be compared with the power curve shown in Figure 2 (straight blue line). Finally, the electrical wave power produced by the WECs is also added to the graph (black diamonds) and normalized at 5MW.

On the one hand, it appears that the mean wind power measured in time domain perfectly matches the power curve. Furthermore, the standard deviation are relatively small, highlighting the weak coupling between the wind and wave power units. In other words, the barge is sufficiently stable to maintain the wind turbine in its optimal configuration.

On the other hand, two different regimes can be observed for wind speeds around $7 \mathrm{~m} / \mathrm{s}$. In fact, the WEC power is predominant for low wind speeds, where the occurences are the highest. The opposite trend can be observed for wind speed between $7 \mathrm{~ms} /$ and $18 \mathrm{~m} / \mathrm{s}$, until the nominal power value is reached for both power units. These results are sensitive to the statistical methods chosen for the selection of the sea sate corresponding to a chosen mean wind speed. Nevertheless, it tends to demonstrate that the power production can be balanced between the different sources of energy.

\section{2 - Performances analysis}

Within the MARINA project, full environmental data have been provided for a few selected European sites. The following section will focus on the "site 14" which corresponds to a point located $30 \mathrm{~km}$ from the Norwegian costs, where the water depth is approximately $200 \mathrm{~m}$ (GPS coordinates : $61.85 \mathrm{~N}, 4.23 \mathrm{E}$ ).

Probability distributions for the mean wind speed $U_{0}$, the significant wave height $H_{s}$, and the peak period $T_{p}$ were extracted from hindcast data. In order to best represent the statistical variability a full 3D calculation was envisaged, following three main steps:

1. Creation of a scatter diagram, representing a $2 \mathrm{D}$ grid with $H_{s} \in[0.25 m: 13.25 m]$ and $T_{p} \in[0.5 s: 16.5 s]$.

2. Determination of the occurrences for 13 values of mean wind speed chosen between $4 \mathrm{~m} / \mathrm{s}$ and $28 \mathrm{~m} / \mathrm{s}$ for each cell in the scatter diagram.

3. Time domain simulation for each sea state and each mean wind speed value (232 sea state $\mathrm{x} 13$ wind speeds $\sim 70 \mathrm{CPU}$ days).

In order to avoid difficulties related to the 3D display of environmental data, it was decided to show the most probable wind speed values together with the corresponding sea state occurrences. These two scatter diagrams are presented in the left column of Figure 6. 


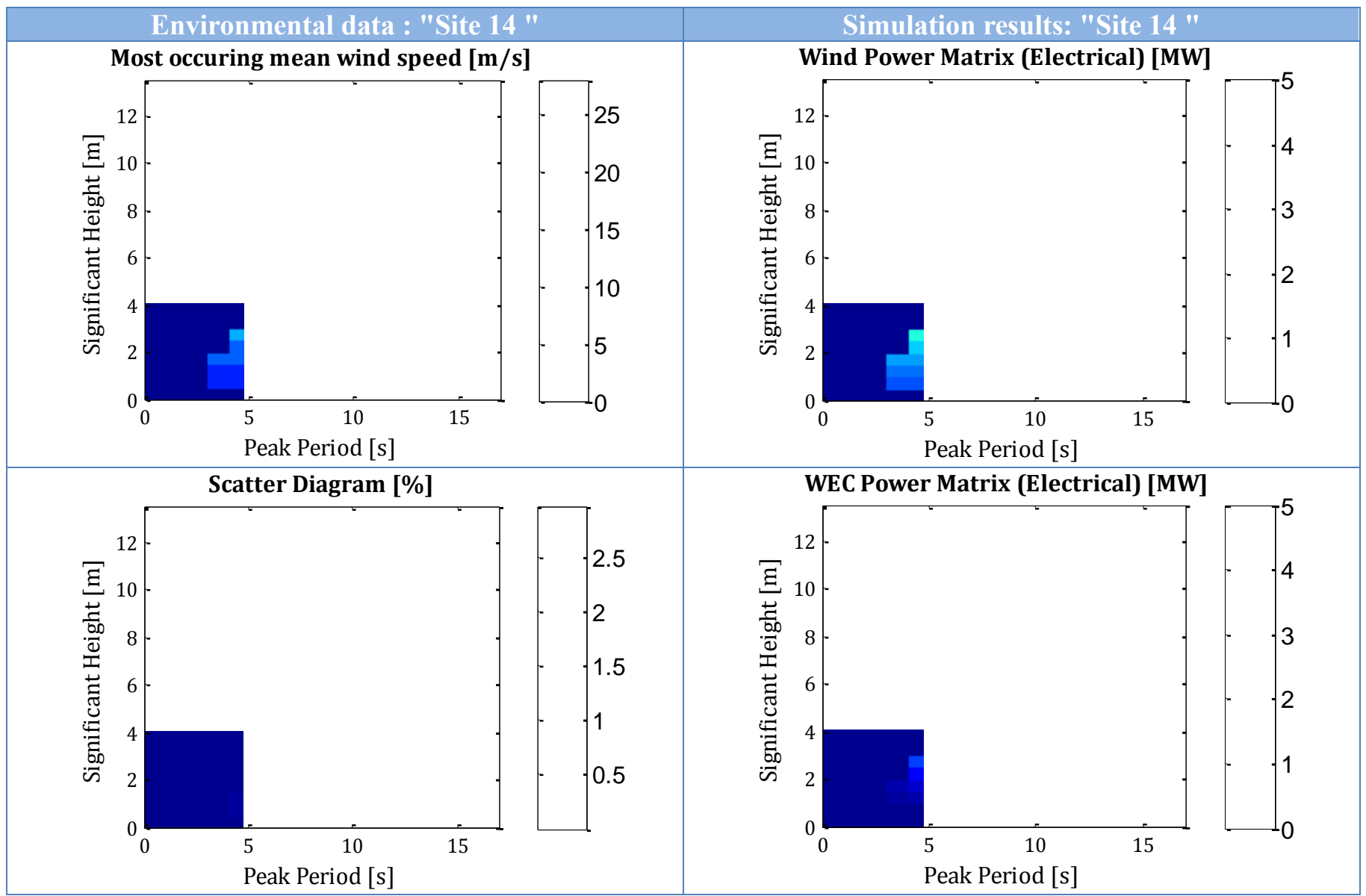

Figure 6: Environmental data and numerical simulation results for "Site 14".

The power outputs from the numerical simulations are shown in the right column of Figure 6. As a matter of consistency, the total rated power of the WECs is set to 5MW. Furthermore, the efficiency of the transfer from mechanical to electrical power through the PTO is set to $65 \%$.

These two matrices show similar trends and amplitudes. Knowing that they represent the absorption capabilities of the platform before taking into account any environmental statistics, it emphasizes the balanced energy contributions.

Eventually, the annual average wave power is obtained multiplying the $3 \mathrm{D}$ occurrence matrix determined in step 2), and the power matrices calculated in step 3). Another site is considered, taken from the project database, and marked at $40 \mathrm{~km}$ from the Portuguese coasts (GPS coordinates: $42.13 \mathrm{~N}$, $9.40 \mathrm{E}$ ). The annual average results for these two sites are summarized in Table 3.

\begin{tabular}{|llcc|}
\hline & Units & Site 14 & Site 3 \\
\hline Wave resource & {$[\mathrm{kW} / \mathrm{m}]$} & 50.5 & 45.1 \\
\hline Wind resource & {$\left[\mathrm{W} / \mathrm{m}^{2}\right]$} & 750 & 370 \\
\hline Electrical WEC power & {$[\mathrm{MW}]$} & 1.52 & 1.25 \\
\hline Electrical Wind power & {$[\mathrm{MW}]$} & 2.11 & 1.45 \\
\hline Total electrical power & {$[\mathrm{MW}]$} & $\mathbf{3 . 6 3}$ & $\mathbf{2 . 7 0}$ \\
\hline
\end{tabular}

Table 3: Annual average power results for $\mathrm{C}-\mathrm{HyP}$.
The annual average wind power for the Norwegian "Site 14" appears particularly high compared to the commonly accepted values of $1.5 \mathrm{MW}$ for a $5 \mathrm{MW}$ rated turbine. This is mainly due to the resource in the Baltic sea, which is the highest in Europe [9]. Indeed, the power produced by the wind turbine at the Portuguese "Site 3" is lower and fairly close to the expected value.

Therefore, for usual Atlantic resource, the production of the CHyP is balanced between wind and wave contributions.

\section{3 - Benchmarking}

The results presented in the previous section were used internally in the MARINA project, in order to compare with other hybrid concepts. However, it seems legitimate to compare the power production of this platform with existing devices from the wave and wind energy domains.

According to [2] the power produced by different types of WECs can be estimated knowing their capture width ratio. The environmental data selected for this comparison corresponds to the French site of Yeu. Table 4 displays together the mechanical power absorbed by the C-HyP flaps and by concepts similar to the Oyster (fixed pitching flap), the Wavestar (oscillating buoys) and the Wavebob (heave oscillating bodies).

The total absorbed power is significantly higher for the WECs of the C-HyP, even though the results are comparable in terms of performance. In fact, the cost indicators are lower for the C- 
HyP (i.e the energy divided by the displacement $\mathrm{V}$ or by the significant surface Stot). In other words, the C-HyP can produce a large amount of power thanks to its large dimensions. However, the size can also become an economical drawback.

\begin{tabular}{|llcccc|}
\hline Site - Yeu & Units & $\begin{array}{c}\text { C-Hyp } \\
\text { WEC }\end{array}$ & $\begin{array}{c}\text { Oyster } \\
\text { "like" }\end{array}$ & $\begin{array}{c}\text { WaveStar } \\
\text { "like" }\end{array}$ & $\begin{array}{c}\text { Wavebob } \\
\text { "like" }\end{array}$ \\
\hline Resource & {$[\mathrm{kW} / \mathrm{m}]$} & 26.2 & 22.4 & 22.4 & 26.2 \\
\hline Abs. power & {$[\mathrm{MW}]$} & 1.89 & $\mathbf{0 . 4 4}$ & $\mathbf{0 . 2 8}$ & $\mathbf{0 . 1 9}$ \\
\hline Capture width & {$[\%]$} & 72 & 72 & 17 & 36 \\
\hline Energy / V & {$\left[\mathrm{MWh} / \mathrm{m}^{3}\right]$} & 0.21 & 1.0 & 1.5 & 0.3 \\
\hline Energy / Stot & {$\left[\mathrm{MWh} / \mathrm{m}^{2}\right]$} & $\mathbf{0 . 8 1}$ & $\mathbf{1 . 9}$ & $\mathbf{0 . 5 6}$ & $\mathbf{0 . 7 9}$ \\
\hline
\end{tabular}

Table 4: Power comparison between $\mathrm{C}-\mathrm{HyP}$ and existing WEC devices.

Furthermore, the total power produced by the platform can be compared with floating wind technologies (see Table 5). In order to calculate the electrical power produced by the $5 \mathrm{MW}$ rated floating wind turbine, the capacity factor was set to $30 \%$. When the different contributions of the C-HyP are considered, it produces more electrical power but at higher cost indicators. Nevertheless, the volume considerations for such devices do not reflect the physical reality. Therefore, a structural analysis phase is required in order to estimate the steel mass of the CHyP.

\begin{tabular}{|llccc|}
\hline Site - Yeu & Units & $\begin{array}{c}\text { HyWind } \\
\text { "like" }\end{array}$ & $\begin{array}{c}\text { Windfloat } \\
\text { "like" }\end{array}$ & $\begin{array}{c}\text { C-Hyp } \\
\text { Tot }\end{array}$ \\
\hline Elec. Power & {$[\mathrm{MW}]$} & 1.5 & 1.5 & 2.73 \\
\hline Energy / V & {$\left[\mathrm{MWh} / \mathrm{m}^{3}\right]$} & 1.88 & 2.8 & 0.31 \\
\hline Energy / Stot & {$\left[\mathrm{MWh} / \mathrm{m}^{2}\right]$} & 1.7 & 0.85 & 1.17 \\
\hline
\end{tabular}

Table 5: Power comparison between $\mathrm{C}-\mathrm{HyP}$ and existing floating wind devices.

\section{3 - DEVELOPMENT PHASE}

\section{1 - Structural analysis}

A tubular steel frame sealed by plates and stiffeners was envisaged for the initial structural design of the C-HyP. The primary objective was to determine the total steel mass required to sustain typical design cases, such as hogging, sagging, and hydrostatic pressure. The self-weight of the platform and the wind induced momentum are taken into account in the model. The following approach was chosen:

1. 2D study: the largest section is designed with FEM to resist the maximal loads.

2. $3 \mathrm{D}$ extension in $\mathrm{x}$ and $\mathrm{y}$ directions to obtain the frame.

3. Design of the plates to sustain hydrostatic pressure with an analytic orthotropic model [10].
The calculations on the beams are based on the Norsok-N004 standards [11]. The analysis focuses on axial and bending loads. The results are expressed as utilization ratios. A ratio greater than 1 represents loads values which are above the breaking limit of the beam. Figure 7 provides an example of the axial ratios in the hogging case for the $2 \mathrm{D}$ section. Iterative design modifications have been carried out in order to reduce the structural mass.

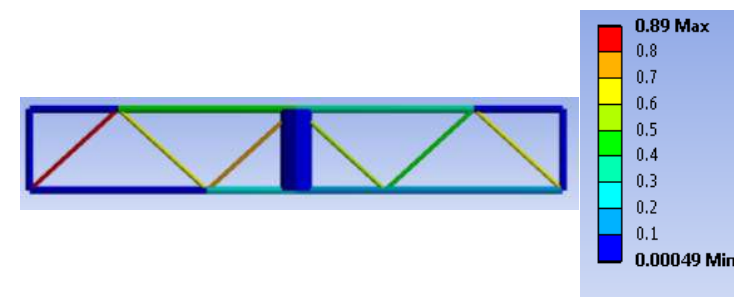

Figure 7: Axial loads utilization ratio.

Figure 8 on the other hand shows the 3D structure which has been designed based on the 2D optimal case. The ratios on Figure 8 correspond to the hogging case as well, the results being summarized in Table 6 and Table 7 . Two of the different configurations tested are compared in terms of loads and structural masses (5R refers to five rows of beams, and $11 \mathrm{R}$ to 11 rows of smaller beams).

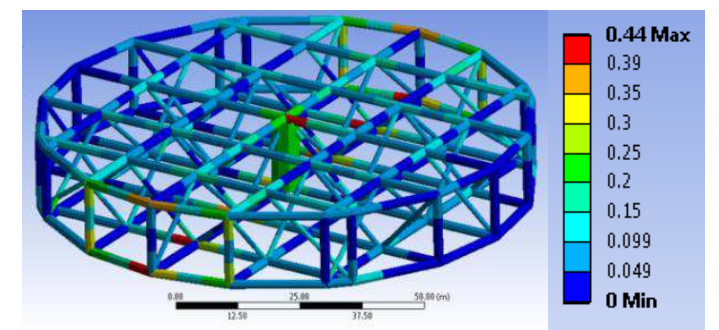

Figure 8: Flexion momentum utilization ratio (5rows structure).

\begin{tabular}{|c|c|c|c|c|c|c|c|c|}
\hline & \multicolumn{2}{|c|}{$\begin{array}{c}\text { Beam } \\
\text { type 1 }\end{array}$} & \multicolumn{2}{c|}{$\begin{array}{c}\text { Beam } \\
\text { type 2 }\end{array}$} & \multicolumn{2}{c|}{$\begin{array}{c}\text { Max. utilization } \\
\text { ratio (" hogging ») }\end{array}$} & \multicolumn{2}{c|}{$\begin{array}{c}\text { Max. utilization } \\
\text { ratio (" sagging } \text { ) }\end{array}$} \\
\hline Ref & $\begin{array}{c}\text { Rin } \\
(\mathrm{m})\end{array}$ & $\begin{array}{c}\text { Rout } \\
(\mathrm{m})\end{array}$ & $\begin{array}{c}\text { Rin } \\
(\mathrm{m})\end{array}$ & $\begin{array}{c}\text { Rout } \\
(\mathrm{m})\end{array}$ & $\begin{array}{c}\text { Axial } \\
\text { criteria }\end{array}$ & $\begin{array}{c}\text { Bending } \\
\text { criteria }\end{array}$ & $\begin{array}{c}\text { Axial } \\
\text { criteria }\end{array}$ & $\begin{array}{c}\text { Bending } \\
\text { criteria }\end{array}$ \\
\hline $\mathbf{5 R}$ & 0.96 & 1 & 0.51 & 0.55 & 0.99 & 0.79 & 0.66 & 0.44 \\
\hline 11R & 0.55 & 0.6 & - & - & 0.64 & 0.95 & 0.35 & 0.35 \\
\hline
\end{tabular}

Table 6: Utilization ratio for two of the configurations tested.

The analysis did not take into account the structural reinforcement due to the plates. Therefore, the whole approach is fairly conservative.

\begin{tabular}{|c|c|c|c|}
\hline & \multicolumn{3}{|c|}{ Steel mass (tonnes) } \\
\hline Ref & Beams & Plates and stiffeners & Total \\
\hline $\mathbf{5 R}$ & $6.5 \mathrm{E}+03$ & $6.7 \mathrm{E}+03$ & $1.3 \mathrm{E}+04$ \\
\hline $\mathbf{1 1 R}$ & $1.1 \mathrm{E}+04$ & $4.2 \mathrm{E}+03$ & $1.5 \mathrm{E}+04$ \\
\hline
\end{tabular}

Table 7: Mass summary. 


\section{2 - Mooring calculation}

The mooring analysis has been carried out with the Orcaflex software, under various simplifications. Indeed, the primary objective was to determine the technical feasibility of a mooring solution, hence the wind loads were not taken into account in the preliminary calculation. The choice of chains instead of cables is a current practice for initial designs in the offshore industry for water depth up to $200 \mathrm{~m}$. Significant chain length allows canceling the vertical loads at the anchors. Nevertheless, Vertical Load Anchors (VALs) could help reducing the footprint if the soil conditions prove to be appropriate.

The design sea state was determined considering the characteristics of the platform. Knowing that the pitch resonance period of the $\mathrm{C}-\mathrm{HyP}$ is $10.8 \mathrm{~s}$, the design peak period was set to $11 \mathrm{~s}$. The other environmental parameters are determined with the contour method presented in [12]. This approach aims at calculating the extreme response of the device applying a correcting factor to the time domain simulation results.

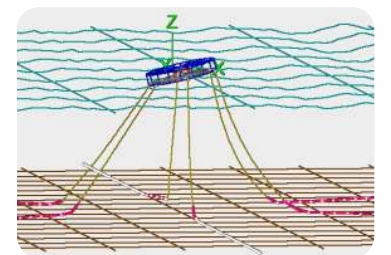

\begin{tabular}{|llc|}
\hline Conditions & Units & Site 14 \\
\hline Peak period & {$[\mathrm{s}]$} & 11 \\
\hline Significant height & {$[\mathrm{m}]$} & 10.8 \\
\hline Current & {$[\mathrm{m} / \mathrm{s}]$} & 1.5 \\
\hline Water depth & {$[\mathrm{m}]$} & 200 \\
\hline Max. excursion & {$[\mathrm{m}]$} & 60 \\
\hline
\end{tabular}

Figure 9: 3Dview and characteristics of the mooring system.

The configurations tested which did not pass the maximum excursion or the breaking criteria were discarded. The influence of clump weights is small considering the already large dimensions of the mooring lines. Nevertheless, it appears that a non-uniform weight distribution along the lines could be an option for optimization.

The selected design contains 6 mooring legs, each containing 3 lines made of $130 \mathrm{~mm}$ diameter chains (see Figure 9). The total cost of such a configuration is high, with a similar order of magnitude than large offshore structures such as FPSOs. Eventually, $10 \%$ of the total cost will be allocated to the installation and deployment.

\section{4 - CONCLUSIONS}

This study summarizes the feasibility analysis of a combined wind and wave energy platform. The selected concept is a circular $100 \mathrm{~m}$ diameter platform set with 20 surge oscillating wave energy converters on the wave facing semi section. A 5MW wind turbine of the NREL type is mounted at the center of the barge.

At first, the total power produced by the platform was assessed with a coupled hydro-aero-dynamic numerical model. For a Norwegian site, the annual average electrical power provided to the grid can reach $3.6 \mathrm{MW}$. The contribution of the wave absorbers is about $42 \%$, which is close to a balanced power production. The comparison with existing technologies turns in favor of the C-HyP in terms of total power production. However, the differences decrease when cost indicators are taken into account.

Preliminary structural and mooring calculations are required prior to a potential industrial development phase. It has been demonstrated that technical solutions for survival conditions exist, even if they remain costly.

The authors are aware of the technical challenges inherent to such large floating combined systems. For instance, the existing shipyards and drydocks might not be sufficient to construct and assemble the C-HyP. However, the main motivation was to demonstrate the feasibility of a concept with balanced wind and wave contributions. Considering the important operational and capital expenditures, it was envisaged to carry on with large platforms through an iterative design phase. The next iteration combines systems with higher technology readiness levels, i.e. a semi-submersible and pitching WECs (see Figure 10). The power results for this platform should be available for the conference presentation.

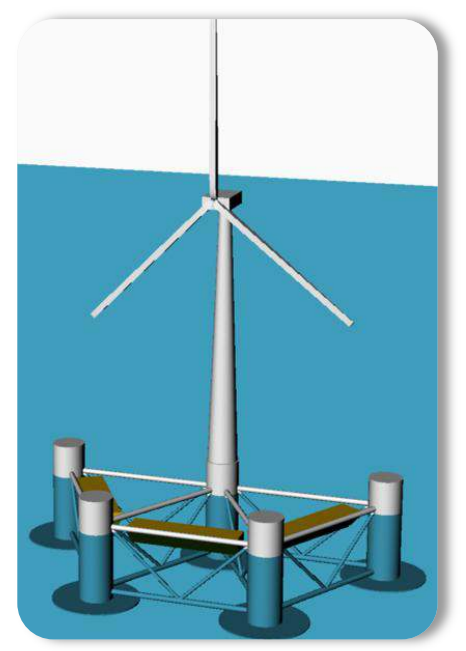

Figure 10: 3D view of a new design for large floating hybrid platform.

\section{ACKNOWLEDGMENTS}

The authors gratefully acknowledge the financial support from the European Commission through the $7^{\text {th }}$ Framework Program (MARINA Platform - Marine Renewable Integrated Application Platform, Grant Agreement 241402) which made this work possible.

\section{REFERENCES}

[1] http://www.marina-platform.info

[2] A. Babarit, J. Hals, M.J. Muliawan, A. Kurniawan, T. Moan, J. Krokstad, 2012. Numerical benchmarking study of a selection of wave energy converters. Renewable Energy, Vol. 41, pages 44-63.

[3] T. Soulard, A. Babarit, 2012. Numerical assessment of the mean power production of a combined wind and wave energy 
platform. Proc. of the International Conference on Ocean, Offshore and Arctic Engineering.

[4] G. Delhommeau, 1997. Seakeeping Code Aquaplus.

[5] M. Karimirad, T. Moan, 2012. A simplified method for coupled analysis of floating offshore wind turbines. Marine Structures

[6] D. Roddier, C. Cermelli, A. Aubault, A. Weinstein, 2010. WindFloat: A floating foundation for offshore wind turbines. Renewable Energy, Vol. 2

[7] J. Jonkman, S. Butterfield, W. Musial, G. Scott, 2009. Definition of a 5-MW Reference Wind turbine for Offshore System Development. National Renewable energy Laboratory.

[8] B. Molin, 2002. Hydrodynamique des structures offshore, Guides Pratiques sur les Ouvrages en Mer, TECHNIP Eds.

[9] ORECCA work package 2. Resource Data and GIS Tool for Offshore Renewable Energy Projects in Europe. ORECCA Project, 2012. http://www.orecca.eu

[10] E. Ventsel, T. Krauthammer, 2001. Thin Plates and Shells : Theory, Analysis, and Applications, The Pennsylvania State University, University Park, Pennsylvania, Marcel Dekker, Inc.

[11] NORSOK STANDARD N-004, 1998. Design of steel structures

[12] M.J. Muliawan, Z. Gao, T. Moan, 2012. Application of the contour line method for estimating extreme response in mooring lines of a two-body floating wave energy converter. Proc. of International Conference on Ocean, Offshore and Artic Engineering. 